\title{
Approaches to learning among Ghanaian students following a PBL-based medical curriculum
}

\section{Victor Mogre, Anthony Amalba}

University for Development Studies, School of Medicine and Health Sciences, Box TL 1883, Tamale, Ghana

\section{ARTICLE INFO}

Received

: 02/10/2014

Accepted : :07/01/2015

Published : :25/03/2015

\section{KEYWORD}

Learning approaches

Medical students

Problem-Based Learning

Study Process Questionnaire

\section{ABSTRACT}

Introduction: Students approaches to learning influences their understanding of the concepts of a subject matter. A learning approach considers the motivation and the strategies employed by the student to learn Objective: To investigate the learning approaches (Deep vs. surface) of medical students following a PBL-based medical curriculum and their association to gender and age. Method: This cross-sectional study was conducted among 189 pre-clinical students following a PBL-based medical curriculum at the School of Medicine and Health Sciences, University for Development Studies, Ghana. Students' learning approaches were assessed using the Biggs's Revised Two Factor Study Process Questionnaire (SPQ) and compared with their demographic factors of gender and age. Linear regression models were employed to determine the predictors of deep and surface approaches to learning. Result: The students were frequently male (60.8\%, $n=115)$; $78.3 \%(n=148)$ aged $18-23$ years and $42.3 \%(n=80)$ in their second year of medical education. Respectively, mean and standard deviation for deep and surface scores were $31.23 \pm 7.19$ and $22.62 \pm 6.48$ $(p=0.0011)$. Gender as well as year of study was neither associated to deep approach nor to surface approach scores. While deep approach scores increased with increasing age $(\beta=0.33, \mathrm{p}<0.01)$, surface approach scores decreased $(\beta=-0.20, \mathrm{p}<0.05)$. Conclusion: Our findings may support the literature that PBL promotes deep approach to learning among students. Deep approach to learning was significantly associated to age but not to gender and year of study.

(c) Medical Education Department, School of Medical Sciences, Universiti Sains Malaysia. All rights reserved.

CORRESPONDING AUTHOR: Victor Mogre, University for Development Studies, School of Medicine and Health Sciences, Box TL 1883, Tamale, Ghana. Email: vmogre@uds.edu.gh

\section{Introduction}

According to Zhang and Sternberg [1], an approach to learning considers the motivation and the adoption of appropriate strategies by students to learn. Biggs et al., [2] adds that an approach to learning outlines the nature of the interaction between the student, context and task. In general, two approaches to learning have been outlined: the 'surface' approach and the 'deep' approach [3]. Students adopting a deep approach are motivated internally to study a subject area [4]. They derive enjoyment from the learning task, learn for understanding and apply the knowledge acquired to real life situations [5]. They critically examine ideas and evidence, use it cautiously and actively and relate new information to prior knowledge. Furthermore, the deep approach is found to facilitate the retention of factual details more effectively [6]. Conversely, surface learners make use of rote learning and memorization, avoid personal 
understanding, and are unreflective about their learning experience [2,7]. Predominantly they are motivated by either a desire to simply complete the course [4] or by a fear of failure [8]. They tend to be anxiously aware of assessment requirements and prefer to restrict learning to a defined syllabus and specified tasks [4]. These students commonly exhibit an extrinsic motivation to learn, unquestioning and the acceptance of everything in the textbook and in lectures [9].

Evaluating students' approaches to learning can help students to become better learners; assist individual teachers to monitor and improve the effectiveness of their teaching; identify students at risk as a result of ineffective strategies; observe the outcomes and experience of learning and evaluating the impact of a new curriculum $[3,6,8,10-12]$

Numerous instruments or inventories have been developed to assess students' approaches to learning. These include the Approaches to Study Inventory (ASI) [13], Biggs' Study Process Questionnaire (SPQ) [14], Inventory of Learning Styles in Higher Education (ILSHE) [15], Approaches to Study Skill Inventory for Students (ASSIST) [16], and the Revised Two-Factor Study Process Questionnaire [2]. All of these inventories/instruments have their strengths and weaknesses.

In the present study Biggs Revised Two Factor Study Process Questionnaire (R-SPQ2F) [2] was used to evaluate the individual student's approach to learning which is determined by their motive and strategy of learning. In response to request for a shorter version of the SPQ, Biggs et al., [2] developed a simple version comprising two factors (deep and surface) with 20 items.

In 2007, the University for Development Studies, School of Medicine and Health Sciences (UDSSMHS) adopted the problem-based learning method of teaching and learning after using the conventional method for 10 years. The UDSSMHS is the first medical school in Ghana to adopt an innovative method of teaching and learning [17]. For the past six years the UDS-
SMHS has been using the PBL methodology without any research on the impact of the curriculum on the learning approaches of students.

A number of factors have been shown to influence students' approaches to learning. Some of these factors have been categorized as personal (e.g., student gender, age, prior experiences) and contextual (e.g., teaching/ learning activities/methods, perceived workload, assessment procedures, institutional values) $[14,18]$. Studies on the study approaches of students and their associated factors are limited in Sub-Saharan Africa including Ghana.

This study was aimed at investigating approaches to learning (Deep vs. surface) among Ghanaian medical students. In addition, the study investigated the influence of gender and age on the learning approaches of the students.

\section{Method}

\section{Study setting and Participants}

In 2007, the UDS-SMHS adopted a ProblemBased Learning, Community-based Education and Service (PBL-COBES) curriculum for the training of its students. The UDS-SMHS is a pioneer in the adoption, implementation and promotion of innovative learning methodology in Ghana. Details of how teaching and learning is carried out using the PBL-COBES curriculum is presented elsewhere [17]. To ensure uniformity of the participants with regards to the type of teaching and learning methodology they were following, first year students were excluded from the study because they were following a conventional method of teaching and learning, described elsewhere [17]. As such we included second, third and fourth year medical students (generally preclinical medical students) into the study. Distribution and collection of questionnaires were coordinated by a staff member. The study was reviewed and approved by the Ethics Committee of the UDS-SMHS.

\section{Instrument}

The Biggs's Revised Two Factor Study Process Questionnaire (R-SPQ2F) [2] was used to 
measure the students' approaches to learning. According to Biggs, a student's learning approach is a function of both a motive and a strategy [12], with the motive influencing the learning and studying strategies that the student adopts [4]. Several studies have demonstrated that students' approaches to learning are contextually dependent and are not stable [19, 20]. This study was done in the pre-clinical context. This questionnaire is unidimensional for each subscale and the subscales are internally consistent [2]. The questionnaire consisted of 20 items on students' approaches to learning. The questionnaire was modified to meet the context of the study. In addition, demographic factors such as age, gender and level of study of medicine were added to the questionnaire. The responses to the questionnaire were analysed according to Biggs [2] scoring system. Each student had scores for deep motive, deep strategy, surface motive and surface strategy. All deep motive and strategy scores were summed to arrive at a deep approach score for a student. All surface motive and strategy scores were summed to arrive at a surface approach score. The maximum possible score was 50 for each of deep or surface approaches consisting of motivation and strategy scores equally whereas the minimum possible score was ten for each approach [21]. The questionnaire had a good level of internal consistency and was also valid for the study [22]. It was self-administered to all students from PBL 1 to PBL 3.

\section{Statistical analysis}

Descriptive statistics of mean and standard deviation for each approach were calculated. Internal consistency of the questionnaire was determined by Cronbach alpha scores. Linear regression models were used to determine the predictors of deep approach and surface approaches to learning. Statistical significant differences between means were set at the 0.05 level. The statistical software GraphPad Prism version 5.00 (GraphPad software, San Diego California USA, www.graphpad.com) for windows was used for the descriptive analysis. SPSS (17.0) was used for calculating the Cronbach alpha and modelling the linear regression models.

\section{Result}

Of the 235 students contacted, 217 returned the questionnaire from which 28 were incomplete, leaving 189 (80.4\% response rate) complete questionnaires for the study. The general characteristics of the students are presented in table 1 . The students were frequently male $(60.8 \%, n=115)$, in their second year of medical education $(42.3 \%, n=80)$ and had a mean age of $22.69 \pm 0.18$ years.

Table 1: Demographic characteristics from PBL 1 to 3 medical students in 2013 at the School of Medicine and Health Sciences, University for Development Studies $(\mathrm{n}=189)$

\begin{tabular}{lll}
\hline Variable & Frequency & \% \\
\hline Sex & & \\
$\quad$ Male & 115 & $60.8 \%$ \\
Female & 74 & $39.2 \%$ \\
\hline Age(yrs) & & \\
$18-23$ & 148 & $78.3 \%$ \\
$24-29$ & 36 & $19.0 \%$ \\
$30+$ & 5 & $2.6 \%$ \\
\hline Mean \pm SD & $22.69 \pm 0.18$ \\
\hline Year group/Level & & \\
PBL 1 (year 2 of med*.) & 80 & $42.3 \%$ \\
PBL 2 (year 3 of med*.) & 64 & $33.9 \%$ \\
PBL 3 (year 4 of med*.) & 45 & $23.8 \%$ \\
\hline * refers to medicine &
\end{tabular}

Table 2: Internal consistency and descriptive statistics of mean and standard deviations of the RSPQ2F from PBL 1 to 3 medical students in 2013 at the School of Medicine and Health Sciences, University for Development Studies ( $n=189)$

\begin{tabular}{cll}
\hline Approach/Scale & Mean & SD \\
\hline Deep approach & $\mathbf{3 1 . 2 3}$ & $\mathbf{7 . 1 9}$ \\
Deep motive & 15.96 & 3.62 \\
Deep strategy & 15.27 & 4.09 \\
Surface approach & $\mathbf{2 2 . 6 2}$ & $\mathbf{6 . 4 8}$ \\
Surface motive & 9.8 & 3.4 \\
Surface strategy & 12.82 & 3.82 \\
\hline
\end{tabular}


Mean and standard deviations scores of the students within the scales and subscales of the questionnaire are presented in table 2 . Significantly students had higher mean scores in the deep approach compared to the surface approach (31.23 vs. 22.62, p=0.0011).

Presented in table 3 are the Pearson productmoment correlations between scales and subscales of the SPQ and some demographic variables. There was a significant positive correlation ( $r=0.92, p<0.01$ and $r=0.94, p<0.01$ ) between the deep approach scale and its two subscales and also between the surface approach scale and its subscales $(0.88, \mathrm{p}<0.01$ and 0.90 , $\mathrm{p}<0.01)$. Age correlated positively with deep motive $(\mathrm{r}=0.27, \mathrm{p}<0.01)$ and deep strategy $(\mathrm{r}=$ $0.21, \mathrm{p}<0.01)$ scores as well as deep approach scores.

Table 3: Pearson Product -Moment Correlations between scales and subscales and demographic variables of the R-SPQ2F from PBL 1 to 3 medical students in 2013 at the School of Medicine and Health Sciences, University for Development Studies $(\mathrm{n}=189)$

\begin{tabular}{|c|c|c|c|c|c|c|}
\hline Variables & DS & SM & SS & DA & SA & AG \\
\hline DM & $0.73^{* *}$ & $-0.24^{* *}$ & -0.10 & $0.92^{* *}$ & $-0.19^{*}$ & $0.27^{* *}$ \\
\hline DS & & $-0.20^{* *}$ & -0.10 & $0.94^{* *}$ & $-0.16^{*}$ & $0.21^{* *}$ \\
\hline SM & & & $0.59^{* *}$ & $-0.23^{* *}$ & $0.88^{* *}$ & -0.10 \\
\hline SS & & & & -0.11 & $0.90^{* *}$ & $-0.19^{* *}$ \\
\hline DA & & & & & $-0.19^{*}$ & $0.25^{* *}$ \\
\hline SA & & & & & & $-0.17^{*}$ \\
\hline GEN & & & & & & -0.11 \\
\hline
\end{tabular}

**. Correlation is significant at the 0.01 level (2-tailed). *. Correlation is significant at the 0.05 level (2-tailed). DM= Deep Motive, DS = Deep strategy, SM= Surface Motive, SS= Surface Strategy, DA=Deep Approach, SA=Surface Approach, and AG=Age,

The relative contribution of the predictor variables of the deep approach scores are presented in table 4 . The linear regression model explains $10 \%$ of the variance in deep approach.
Increase in age significantly predicted an increase in deep approach scores $(\beta=0.33$, $\mathrm{p}<0.01)$

Table 4: Linear regression of variables predicting deep approach learning from PBL 1 to 3 medical students in 2013 at the School of Medicine and Health Sciences, University for Development Studies (n=189)

\begin{tabular}{lccc}
\hline Variable & B (SE) & B & 95\% CI \\
\hline (Constant) & $12.48(4.69)$ & & $3.22-21.74$ \\
Gender (1=Male) & $0.63(1.04)$ & 0.04 & $-1.41-2.67$ \\
Age & $0.95(0.22)$ & $0.33^{* *}$ & $0.51-1.40$ \\
Year of study & $-1.80(0.70)$ & $-0.20^{*}$ & $-3.17--0.43$ \\
\hline
\end{tabular}

$\mathrm{R}^{2}=0.10, \mathrm{p}<0.01 .^{* *} . \mathrm{p}<0.01,{ }^{*} \mathrm{p}<0.05$

The linear regression model in table 5 shows the relative contribution of predictor variables of surface approach scores. Explaining 3\% of the variance in our linear regression model, increasing age predicted a significant decrease in surface approach scores $(\beta=-0.20, \mathrm{p}<0.01)$. 
Table 5: Linear regression of variables predicting surface approach to learning from PBL 1 to 3 medical students in 2013 at the School of Medicine and Health Sciences, University for Development Studies (n=189)

\begin{tabular}{lccc}
\hline Variable & B(SE) & $\boldsymbol{\beta}$ & $\mathbf{9 5 \% ~ C I}$ \\
\hline (Constant) & $33.04(4.39)$ & & $24.38-41.69$ \\
Gender (1=Male) & $0.32(0.97)$ & 0.02 & $-1.59-2.23$ \\
Age & $-0.51(0.21)$ & $-0.20^{*}$ & $-0.92--0.10$ \\
Year of study & $0.52(0.65)$ & 0.06 & $-0.76-1.81$ \\
\hline
\end{tabular}

$\mathrm{R}^{2}=0.03, \mathrm{p}=0.18 .^{* *} . \mathrm{p}<0.01,{ }^{*} \mathrm{p}<0.05$

\section{Discussion}

In the present study, the deep approach recorded the highest scores making it the dominant learning approach among the students. In contrast to our findings a study by Martenson [23] among students following a traditional medical curriculum recorded surface scores as the highest. Several studies among pre-clinical students have also recorded higher surface scores $[4,6,8,21,24]$. The high deep scores found among pre-clinical students in this study could be as a result of the PBL teaching and learning methodology. In a comparison of traditional and PBL curriculum, Newble \& Clarke [25] found that the traditional curriculum was associated with a surface approach whereas PBL fostered a deep approach. This same finding has also been observed in a study by Tetik et al., [21] in a study that assessed students' learning approaches at Medical Schools applying different curricula in Turkey. PBL has characteristics such as early encounter with clinical problems and selfdirected learning which has been shown to promote deep approaches to learning among students [21, 26]. These characteristics promote intrinsic motivation which are associated with the deep learning approach [27, 28]. In the absence of a comparison group in our study, we only postulate the likelihood that our PBL based curriculum which has the above characteristics might have enhanced the learning experience of our students resulting in higher scores in the deep approach. We however, suggest an elaborate study that considers two groups following different curricula (traditional vs. $\mathrm{PBL}$ ) to confirm or disprove our findings.
From our linear regression model, there were no significant associations between gender and students' approaches to learning. In keeping with our findings Rajendra Kumar et al., [29] did not find a difference between gender and students approaches to learning among first and second year medical students in Malaysia. Another study by Samarakoon, Fernando \& Rodrigo [16] among preclinical students in Sri Lanka did not find statistically significant differences between male and female students and the median scores of their approaches to studying. This presupposes that gender did not have an effect on learning approaches in this study.

Another important finding of our study was the fact that as deep approach scores increased with an increase in age, surface approach scores decreased. In Biggs [14] Presage Process Product model (3P model), age has been considered as a personal presage factor which has been shown to influence student approaches to learning [5, 30]. In agreement with our findings, Duff [31] found that age was positively correlated with deep approach and metacognitive awareness and negatively correlated with surface approach.

Research has shown that approaches to learning are not permanent and may change depending on the situation. This has been explained by the Biggs 3P model that recognizes changeability as well as the significance of learning approaches in the learning process. Learning approaches are thus dynamic. Studying a group of students at a point in time would not be adequate to provide fair assessment of their learning approaches. This study therefore serves as a baseline for a longitudinal study to establish the learning 
approaches of the students as well as the factors that affect them.

\section{Conclusion}

The Deep approach was the most predominant approach employed by the students. Gender was neither associated to the deep approach nor to the surface approach. Deep approach scores increased with an increase in age and surface approach scores increased with a decrease in age. Students and teachers should be encouraged to continuously use the deep approach for teaching and learning.

\section{Acknowledgement}

Authors wish to thank Dr. Razak Abizari and Dr. Abass Alhassan for their guidance and encouragement as well as Mr. Suara Sufyan for helping in the data collection. Authors also wish to thank the students who participated in the study.

\section{Reference}

1. Zhang LF, Sternberg RJ. Are learning approaches and thinking styles related? A study in two Chinese populations. J Psychol 2000, 134:469-489.

2. Biggs J, Kember D, Leung DY. The revised two-factor Study Process Questionnaire: RSPQ-2F. Br J Educ Psychol 2001, 71:133149.

3. Marton F, Saljo R. On qualitative differences in learning: I. Outcome and process. British Journal of Educational Psychology 1976, 46:4-11.

4. Emilia O, Bloomfield L, Rotem A. Measuring students' approaches to learning in different clinical rotations. BMC Med Educ 2012, 12:114.

5. Serife AK. A Conceptual Analysis on the Approaches to Learning. Educational Sciences: Theory \& Practice 2008, 8:707720.

6. Abraham RR, Vinod P, Kamath MG, Asha $\mathrm{K}$, Ramnarayan K. Learning approaches of undergraduate medical students to physiology in a non-PBL- and partially PBL-oriented curriculum. Adv Physiol Educ 2008, 32:35-37.

7. Tiwari A, Chan S, Wong E, Wong D, Chui C, Wong A, Patil N. The effect of problem- based learning on students' approaches to learning in the context of clinical nursing education. Nurse Educ Today 2006, 26:430438.

8. Newble DI, Entwistle NJ. Learning styles and approaches: implications for medical education. Med Educ 1986, 20:162-175.

9. Felder RM, Brent R. Understanding student differences. Journal of Engineering Education 2005, 94:57-72.

10. Entwistle NJ. Styles of Learning and teaching; an integrated outline of educational psychology for students, teachers and lecturers. Chichester: John Wiley; 1981.

11. Ramsden P. Learning to teach in higher education. London. London: Routledge; 1992.

12. Biggs J. What do inventories of students' learning processes really measure? A theoretical review and clarification. $\mathrm{Br} \mathrm{J}$ Educ Psychol 1993, 63 ( Pt 1):3-19.

13. Entwistle NJ, Ramsden P. Understanding student learning. London: Croon-Helm; 1983.

14. Biggs JB. Students approaches to learning and studying. Hawthorn: Australian Council for Educational Research; 1987.

15. Vermunt JD. Inventory of learning styles in higher education. Maastricht: Maastricht University; 1994.

16. Samarakoon L, Fernando T, Rodrigo C. Learning styles and approaches to learning among medical undergraduates and postgraduates. BMC Med Educ 2013, 13:42.

17. Mogre V, Amalba A. Medical students' achievement on the Bachelor of Medicine, Bachelor of Surgery/Chirurgery (MBChB) part I and II licensing examination: a comparison of students in problem-based learning community-based education and service and conventional curricula in G. Journal of Educational Evaluation for Health Professions 2014, 11:10.

18. Zeegers $\mathrm{P}$. Approaches to learning in science: a longitudinal study. $\mathrm{Br} \mathrm{J}$ Educ Psychol 2001, 71:115-132.

19. Birenbaum M. Assessment preferences and their relationship to learning strategies and orientation. High Educ 1997, 33:71-84.

20. Kember D, Jamieson QW, Pomfret M, Wong ETT. Learning approaches, study time and academic performance. High Educ 1995, 29:329-343.

21. Tetik C, Gurpinar E, Batı H. Students' Learning Approaches at Medical Schools Applying Different Curricula in Turkey. Kuwait Medical Journal 2009, 41:310-315. 
22. Mogre V, Amalba A. Assessing the reliability and validity of the Revised Two Factor Study Process Questionnaire (RSPQ2F) in Ghanaian medical students. Journal of Educational Evaluation for Health Professions 2014, 11:19.

23. Martenson D. Students' approaches to studying in four medical schools. Medical Education 1986, 20:532-534.

24. Coles CR. Differences between conventional and problem-based curricula in their students' approaches to studying. Med Educ 1985, 19:308-309.

25. Newble DI, Clarke RM. The approaches to learning of students in a traditional and in an innovative problem-based medical school. Med Educ 1986, 20:267-273.

26. Ramsden P, Entwistle N. Effects of Academic Departments On Students'approaches To Studying. British Journal of Educational Psychology 1981, 51:368-383.

27. Kember D, Gow L. Cultural specificity of approaches to study. British Journal of Educational Psychology 1990, 60:356-363.

28. Watkins D: Identifying the study process dimensions of Australian university students. Australian Journal of Education 1982, 26:76-85.

29. Rajendra Kumar L, Voralu K, Pani S, Sethuraman K. Association of Kinesthetic and Read-Write Learner with Deep Approach Learning and Academic Achievement. Canadian Medical Education Journal 2011, 2:e23-e27.

30. Groves M. Problem-based learning and learning approach: is there a relationship? Advances in Health Sciences Education 2005, 10:315-326.

31. Duff A. Understanding academic performance and progression of first-year accounting and business economics undergraduates: the role of approaches to learning and prior academic achievement. Accounting Education 2004, 13:409-430. 